\title{
Horticultural Import Diversification by U.S. Cucumber Processors: A Monte Carlo Risk Assessment
}

\author{
Byron L. Frenz ${ }^{1}$ and \\ Jack E. Staub ${ }^{2}$
}

\begin{abstract}
AdDitional INDEX wORDS. processed cucumbers, feasibility study, purchasing risk, export risk, risk models, diversification strategy, investmentrisk model, marketing risk
\end{abstract}

Summary. Development projects in developing countries are generally considered to be speculative investments. Potentially significant returns on investment opportunities are often overlooked by assuming that investment risks in developing countries are greater or less manageable than the risks of investment in developed countries. An import purchasing-risk evaluation identified the costs associated with the production and export of processing cucumbers (C ucumissativus L.) from $H$ ispaniola ( $H$ aiti and the Dominican Republic) to the U nited States. Although production and export analyses suggested that $\mathrm{H}$ ispaniola might not replace M exico as the primary source of cucumbers for processing in the $\mathrm{U}$ nited States between $\mathbf{N}$ ovember and A pril, $\mathbf{H}$ ispaniola affords the $\mathbf{U}$.S. processing industry with an alternative investment option for reducing single-sourcing raw product risk. Therefore, an import diversification evaluation was conducted using $M$ onte $C$ arlo simulation to define a investment-risk model. Monte $\mathrm{C}$ arlo simulations of the means and variances of the components of cost and

The cost of publishing this paper was defrayed in part by the payment of page charges. U nder postal regulations, this paper therefore must be hereby marked advertisement solely to indicate this fact.

${ }^{1}$ Former graduate student; currently vice president, $\mathrm{N}$ atural Technologies, LLC, M adison, Wis.

2U SDA-ARS research horticulturist and professor of horticulture, 1575 Linden D r., D epartment of $\mathrm{H}$ orticulture, U niversity of W isconsin, M adison, WI 53706;

to whom reprint requests should be addressed. 
price were used to assess investment risk under various investment strategies. This model identified sources of cost variation which were then used to characterize export risks derived from growing processing cucumbers on $H$ ispaniola. It was determined that U.S. processors can reduce overall purchasing-risk by diversifying M exican production to $\mathrm{H}$ ispaniola. Through the creation of a strategic transportation alliance between the $U$.S. and $H$ ispaniola project participants, the export-import costs were such that the investment-risk model identified the allocation of $80 \%$ of the production in Mexico and $20 \%$ in $\mathrm{H}$ aiti as the most favorable diversification strategy. This strategy offered less risk and greater potential longterm returns than purchasing cucumbers solely in M exico.

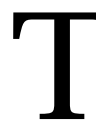

he trend in agricultural trade in Latin American countries is a shift from concentrating on a single primary product such as sugar from sugar cane (Saccharum officinarum L.), coffee (C offea arabica L.), and bananas (M usa acuminata Colla) to exporting a more diversified array of fruitsand vegetables (U SD A, 1991). L atin America's strade composition has recently shifted to new products such as mango (Mangifera indica L.). Intensively managed vegetables such as processing cucumbers might also be considered in such agricultural diversification.

$\mathrm{H}$ ispaniola has historically engaged in limited agricultural tradewith the U nited States. The 1990 value of fruits, vegetables and plants shipped from $L$ atin American countries to the U nited Stateswas $\$ 2,396$ million, from M exico it was $\$ 1,437$ million, from the D ominican Republic (DR) it was $\$ 48$ million, and from $\mathrm{H}$ aiti it was $\$ 7$ million (U SD A, 1991). The value of $\mathrm{H}$ aiti's mango exports ( $\$ 4.5$ million) was greater than the value of traditional crops such as sugar ( $\$ 3.0 \mathrm{mil}$ lion), coco [Eulophia alta (L.) Fawc. and Rendle] ( $\$ 2.4$ million) and coffee (\$1.2 million) [(J.C. Currelly, personal communication).

Based on this trend and the fact that $\mathrm{M}$ exico is the sole raw product source for processing cucumbers to the U nited States during the winter and early spring months, public institutions and private enterprises in $\mathrm{H}$ ispaniola accepted a proposal by the

Horflechnology • J uly-September 1999 9(3) authors to determine the feasibility of establishing a processing cucumber industry (Frenz and Staub, 1999). This proposal was also supported by the U.S. cucumber processing industry which wanted to identify a means of reducing single-sourcing risk.

I nvestment decisions are defined by criteria affecting expected profit maximization that is based on comparisons of investment returns. Therefore, as part of the proposal, afeasibility analysis of processing cucumbers produced in $\mathrm{H}$ ispaniola and exported to the U nited States was also performed (Frenz and Staub, 1999). T his analysis used comparative production and transportation costs in Mexico, the $\mathrm{DR}$, and $\mathrm{H}$ aiti to determine potential returns on investment. These costs were compared to costs of cucumber production at a location in the $U$ nited States(M ichigan) to provideabaseline for futurefeasibility analysesthat would compare domestic to foreign production alternatives. Theproduction analysis determined that, under a given set of constraints, the expected mean returns for U.S. cucumber processors from production in M exico could be greater than that from $\mathrm{H}$ ispaniola.

Although this analysis concluded that exclusive cucumber production in $M$ exico can maximize profit, the comparisons made were simplistic. It is well established that investors are risk averse; that is, they not only consider expected returns (mean bushels/ unit area) but also the variation in those returns (deviations about expected returns). Given a predictable degree of variation in cost, investors (e.g., U.S. cucumber processors) are often willing to accept reductions in expected returns if the overall variation in the investment is small. A more complex, more interesting, and more relevant evaluation of a development project therefore would consider variations in profits as well as expected profits. Therefore, a study was designed to use cucumber production and export data (Frenz and Staub, 1999) to construct an investment-risk model to assess investment risk for agribusiness participants in the $U$ nited States and $\mathrm{H}$ ispaniola. This study sought to determine: 1) whether the current U.S. cucumber export-production model is adequate for marketing-risk analysis, and; 2) if international strategic alliances(SA) among U .S. cucumber processors, $\mathrm{H}$ ispaniola growers and/ or airlines could reduce overall costs and financial risks to satisfy competitive investment criterion.

The risk analysis used identifies and measuresfactorsthat havepotential for controlling risk. This information was then incorporated into the decision-making process to determine the optimal investment strategy. Thus, the risk analysis described herein considers possibilitieswheresimplemaximization of expected mean returns may not be the best investment strategy.

\section{Materials and methods}

This study uses production and export data (Frenz and Staub, 1999) in $\mathrm{M}$ onte $\mathrm{C}$ arlo simulation to evaluate risk. Continuous investment scenarios were identified by simulation that allowed for the evaluation of diversification of foreign growing locations for import of processing cucumbers (raw product) for processing in the $U$ nited States Cost and production inputs formed the basis of an investment-risk model, which calculated investment returns.

RISK Definition. The word risk conveys different meanings and is frequently used without a clear definition (Seal, 1969). While early theories of risk defined the risk-bearer theorem of entrepreneurship in qualitative terms (Knight, 1921), more recently risk theory and risk assessment have becomehighlyquantitative (B righam and Gapenski, 1988; Picciotto, 1994). The quantitative assessment of investment risk for developing countries includes problems such as a limited availability of verifiable data, the complex comparability of international data, and the conflict between business profit objectives and economic development objectives (Brown and Goldin, 1992). Because these inherent limitations to a quantitative assessment of risk analysis, risk in our study was defined and measured by the variance about the expected mean of return on investment and not "a chance (or probability) of loss" (Seal, 1969).

Risk identification. Crops grown outside of the $U$ nited States are subject to risk from fluctuating exchange rates, tariffs, and complex transport expenditures. $M$ any major export cost components fluctuate widely, and are thus important considerations when importing perishable crops such as cucumbers.

$\mathrm{R}$ isk analysis involves the charac- 
terization of a distribution for each component or variable measured. We examined cross-sectional (between countries) variations of cost components for processing cucumber production and export (Frenz and Staub, 1999) in a series of independent experiments (i.e., variety trials and production trails) to identify relationships among components during a specific time period in $\mathrm{H}$ ispaniola. I dentification of the potential elements of risk, the first step of risk analysis, was performed by an examination of each component of costsand returns (Frenz and Staub, 1999). These data provided measured criteria (variables) for thestatistical measurement of risk (i.e., certainty differences in transport distanceand capital investment) by analysis of the probability distributions that characterize possible financial outcomes.

A project cost accounting system allowed for the preparation of recurrent audits to identify causes for variation asso ciated with theimportation of processing cucumbersfrom $\mathrm{H}$ ispaniola (e.g., quantities and ratesfor labor and materials, specific dates, amounts, and vendors) (Frenz, 1996). Cost accounting systemsorganized datawhich were then used to evaluate variations for each cost component. Standard sensitivity analysis procedures were used to rank the cost component's relative influence on price risk (Bodie et al., 1989; N iehans, 1968).

INVESTMENT-RISK MODEL. D ecisionmaking with multiple objectives in businessand government requirescomplex analyses. Several alternative approaches can be used for decisionmaking analysis (Brigham and Gapenski, 1988). We used Monte C arlo simulation followed by sensitivity analysis of production and export data (Frenz and Staub, 1999) for evaluating the diversification of cucumber production to the Caribbean (Brigham and $G$ apendnski, 1988; Frenz, 1996). This method was used because it: 1 ) employed a measure of risk (variance of returns) as defined above; 2) used the actual distributions of costs and returns, and; 3 ) provided for a large number of simulations that could be assessed assingledistributions of profit. The investment-risk model used in this study was programmed for use in SAS (SAS Institute, 1988), and the output (an array of scenarios) was employed in risk assessment.
Monte Carlo simulation. During $\mathrm{M}$ onte $\mathrm{C}$ arlo simulation, distributions were generated under assumptions originating from a production and export data set (Frenz and Staub, 1999). Such distributions are hereafter referred to as scenarios, and were used to evaluate expected return risk and to identify the statistical robustness of investment strategies. $M$ onte Carlo simulations used these data to produce synthetic outco mes of returns (Frenz, 1996) that were based on a variety of plausible scenarios. O utcomes of returns were examined as a distribution of cost per bushel, where the cost was calculated in U.S. dollars (\$) and 1 bushel $=26.6 \mathrm{~kg}=58.6 \mathrm{lb}$. A mean and variance wascalculated for each distribution evaluated. Variances about individual means resulting from the simulation model were a function of deviations associated with mean observations across the countries evaluated using 1991 cost estimates.

The distribution of shipping costs, exchange rates, tariffs, labor, packaging, material in puts, etc. for each country were obtained from $\mathrm{Frenz}$ and Staub (1999) and used as input variables for M onte Carlo simulation. An observation was created by drawing each of the random components of return. The following formula was used for returns: return $(r)=$ price $(p)$ less labor costs (I), materials costs $(m)$, fixed costs (fc), freight (fr), packing plant $(p p)$, and border costs (bd) r i $=p i-I$ $i-m i-f c i-f r i-p p i-b d i$, or where i was one of 8,000 observation-based scenarios. M odel variables were integrated during each of $8,000 \mathrm{M}$ onte Carlo simulations to provide an artificial history of return. The processor's return was defined as the difference between the contracted price and the value to the processor. M ore specific information on the investment-risk model algorithm is presented in Frenz (1996) and Staub (1999).

Theinput dataidentified thelocal currency used to purchase native components of production costs and converted these costs to U.S. dollars (\$). Theconversion factorsemployed were: 3,000 M exican pesos/ U .S. \$, $5 \mathrm{H}$ aitian gourdes/ U.S. \$, and 6.28 DR pesos/ U .S. \$. These conversion rates werebased on 1990 international banking exchange rates. The exchange rate conversions were the first tasks in the sequence of computations and set the mean costs for $\mathrm{M}$ exico, $\mathrm{H}$ aiti, and the
DR in U.S. \$ (Frenz, 1996). The second computation assigned a probability for either low or high freight mean costsfor scenariosto test whether transportation costs (Frenz and Staub, 1999), as created by strategic alliances, were a significant factor in the analyses. The third computation set the standard deviation (SD) of costs as a proportion of each purchasing return mean based on the central limit theorem (Snedecor and Cochran, 1967). For example, setting the SD to (mean $x$ 0.25 ) results in a value that defines mean range (e.g., 1 sD about the mean $=68 \%$ ) where observations are within $25 \%$ of the mean. Thus, if the mean was $\$ 10.00,68 \%$ of the observations were within therange $\$ 7.50$ to $\$ 12.50$. The fourth computation set the grower's profit as a percentage of costs (sign either - or +). This percentage was varied for an array of diversification scenarios (e.g., M exico $80 \%$ and $\mathrm{H}$ aiti $20 \%$ ).

Assessment OF InVestment ReTURNS. The distribution of returns was used to evaluatealternativeinvestment strategies given various diversification scenarios using the variances of component costs (Frenz, 1996). In this experiment, the alternative to $M$ exico was $\mathrm{H}$ aiti or the D R or some combination of M exico, $\mathrm{H}$ aiti and the $\mathrm{DR}$. $V$ arianceanalyses were performed that considered alternative scenarios in which joint production returns ( $\mathrm{C}$ aribbean and $\mathrm{M}$ exico) were compared to single sourcing from M exico (SAS Institute, 1988).

Thedistribution of overall returns can be calculated under various diversified (e.g., Mexico $80 \%$ and $\mathrm{H}$ aiti $20 \%$ ) or undiversified (sole source) investment strategiesif individual components are known (i.e., components of costs per bushel for a growing location). These combinations provided data for the analyses of joint distributions [e.g., diversified scenarios of M exico (80\%)/ D R (20\%) vs. M exico (80\%)/ H aiti (20\%)]. The optimum investment diversification strategy was tested by changing the percent of cucumbers purchased from a country, and then identifying the percent diversification valueswhich yielded thehighest mean (return) and lowest SD (risk) (Frenz, 1996). For example, the diversification strategy of $80 \% \mathrm{M}$ exico and $20 \% \mathrm{H}$ aiti can be changed to a diversification of $75 \%$ M exico, $25 \% \mathrm{H}$ aiti. This change would yield a different 

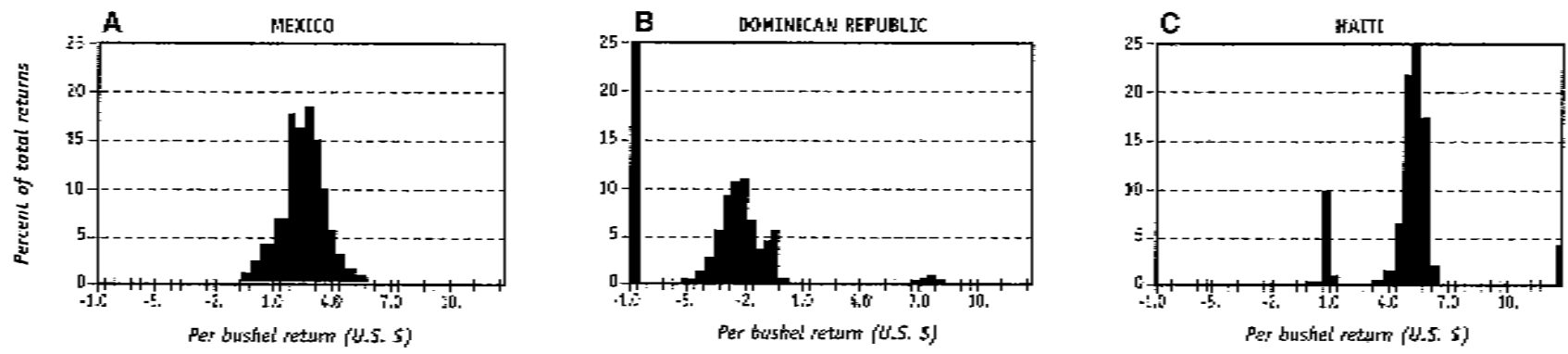

Fig. 1. Per-bushel return (U.S. dollars) from investment in processing cucumber export from M exico, D ominican Republic, and $\mathrm{H}$ aiti to a U.S. processing facility (Woodstock, III.). Purchasing return to the processor is given as percent of total return for M exico by ground transport, and the DR and $\mathrm{H}$ aiti by fixed sea transport in undiversified investiment scenarios based on M onte C arlo simulation and sensitivity analysis of data from an investment-risk model.

mean and SD because components of cost are variable.

Sensitivity analysis was used to identify theparticular percentagewhere the investment allocation among different countries was the optimum balance of return and risk for a particular investment scenario (Brigham and Gapenski, 1988). A cost variable was changed in theinvestment model while other variables are held constant. Repeated simulations yielded an array of possiblereturnsgiven themodel'sconstraints. The returns (independent variable) for each scenario were regressed against the model variable that was changed (dependent variable) (Snedecor and Cochran, 1967). Comparative analyses of regression slopes of return expectations revealed the relative sensitivity of variables in each scenario (the steeper the slope, the more sensitive to change is the variable).

Depiction of Results. Sensitivity analyses allowed for the identification of possible investment scenarios that would might optimize return on investment depending on production and export factors (e.g., transportation), and gave insight into which model components affected diversification outcomes (data not presented; Frenz, 1996). We then used the SAS program input data to define the mean and distribution of components of costs and prices for these scenarios (Frenz, 1996; SAS Institute, 1988). M onte Carlo simulationsusing thesedata provided investment return values (observations) on a cost per bushel basis, and the mean and SD of each return was calculated and graphed for each scenario.

Comparisonsweremadebetween $\mathrm{H}$ aiti as a sole source (lowest production costs; Frenz and Staub, 1999) and the $D R$ and Mexico under differing diversification strategies. The various diversification strategies were themselvescompared to other undiversified scenarios. And finally, comparisons were made between diversification strategies having identical transportation elements. O nly those scenarios that provided for critical comparisons among potential diversification strategies are presented.

T otal returns (\%; y axis) are given for each diversification scenario as a function of observations (the result of one simulation) made during a series of $\mathrm{M}$ onte $\mathrm{C}$ arlo simulations. The distribution of returns of each scenario for each country studied (i.e., sum of each country return $=$ joint return) consisted of 8,000 observations. Thus, if 800 of 8,000 total observed returns were in the range of $\$ 1.00$ to $\$ 1.05 /$ bushel, a frequency of $10 \%$ was assigned to that cost per bushel interval ( $x$ axis).

Partitioning of processor risk commitments (production contracts) for production diversification differed for each scenario. The relative cost per bushel for each diversification scenario differs due to input variables. These costs (U.S. \$/ bushel) are given for each country without diversification and for unique diversified strategies as a distribution of returns (per bushel return) each with its associated mean and SD (Figs. 1-5). A comparison of means and their SD values provided comparative analysis of diversification strategies (i.e., risk and return) among countries. 0 ne strategy was defined as superior to another strategy when it had both a higher mean return and a lower SD value. Within-scenario comparisons (e.g., fixed air transport) were madeby contrasting appropriatemeans and SD values of diversified scenarios (e.g. $80 \%$ M exican; $20 \% \mathrm{H}$ aitian) with the estimated returns from undiversified scenarios.

\section{Results and discussion}

The characterization of flexible and progressivemodels for sustainable cucumber production in developing countries requires the evaluation of import and export financing risk. Analysis of the experimental observations made during this study provided purchasing and marketing-risk modelsfor growers, exporters, and U.S. processors, which may be used for the establishment of a processing cucumber industry in the Caribbean. Such models must be considered along with investment criterion during the development of a potential industry.

$M$ onte Carlo and sensitivity analyses defined export and import financing risk. Since transportation was identified as the critical investment factor (Frenz and Staub, 1999), investment strategies that considered transportation options (fixed and variable air and sea transport) as a function of per bushel return on investment were examined (Fig. 1-5). The distribution for predicted returns of undiversified processor commitments to M exico (ground), the DR (sea), and $\mathrm{H}$ aiti (sea) are presented in Fig. 1. Transportation method can differ [e.g., air (Figs. 2-3) or sea (Fig. 4)], and in the case of diversification of freight rate can beeither fixed (constant; Figs. 1, 2, 3 and 5) or variable (Fig. 4).

Sole source investment. Simulated returns where $M$ exico is used as the sole production source (Fig. 1, panel A) were lower than other diversified strategies (Fig. 2, panel B; Fig. 5, panel B) (Frenz, 1996). M exico (ground transport) provided less risk (based on means and SD values of potential returns) and was a more de- 

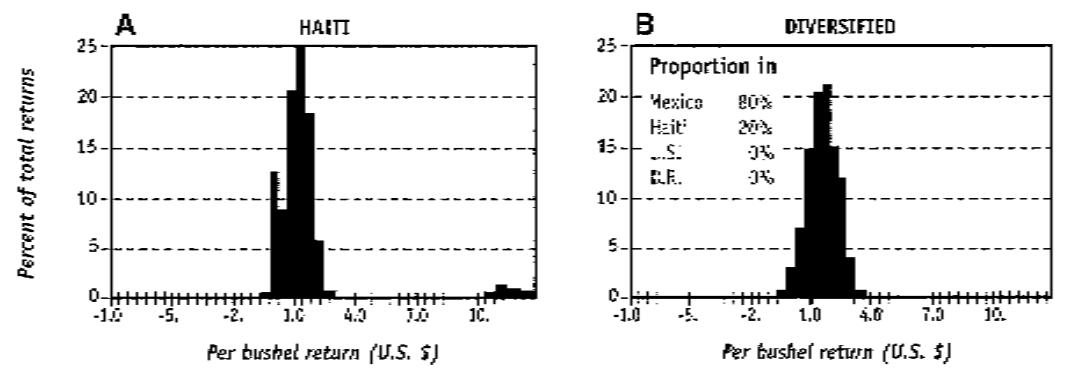

Descriptive statistics for returns (U.S. \$)

Fig. 2. Per-bushel return and descriptive statistics (U.S. dollars) from investment in processing cucumbers exported either solely from $\mathrm{H}$ aiti or from M exico ( $80 \%)$ and H aiti $(20 \%)$ (diversified) to a U .S. processing facility (W oodstock, III.). Purchasing return is given as percent of total return via air transport at a fixed rate based on $\mathrm{M}$ onte $\mathrm{C}$ arlo simulation and sensitivity analysis of data from an investment-risk model.
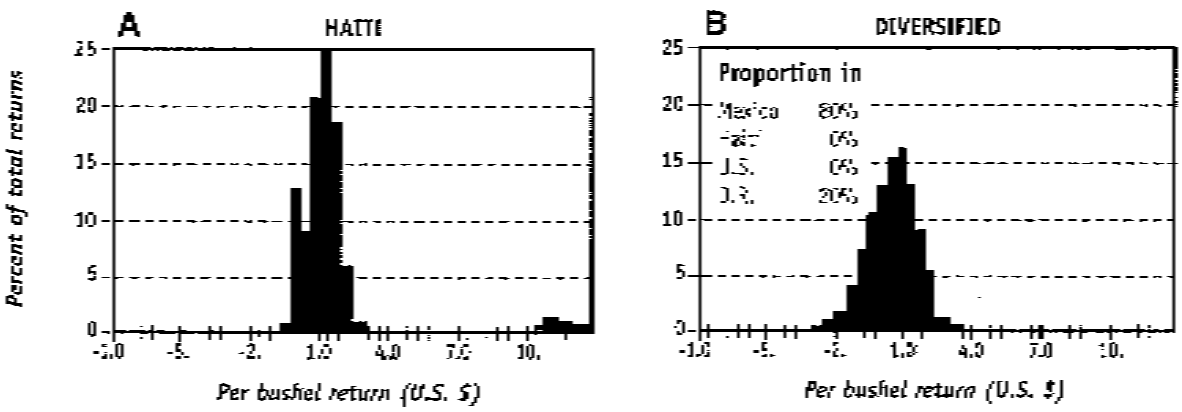

Descriptive statistics for returns \{U.S. \$)

Fig. 3. Per-bushel return and descriptive statistics (U.S. dollars) from investment in processing cucumbers exported either solely from $\mathrm{H}$ aiti or from M exico (80\%) and the Dominican R epublic (D R; 20\%) (diversified) to a U .S. processing facility (W oodstock, III.). Purchasing return is given as percent of total return via air transport at a fixed rate based on Monte $\mathrm{C}$ arlo simulation and sensitivity analysis of data from an investment-risk model.
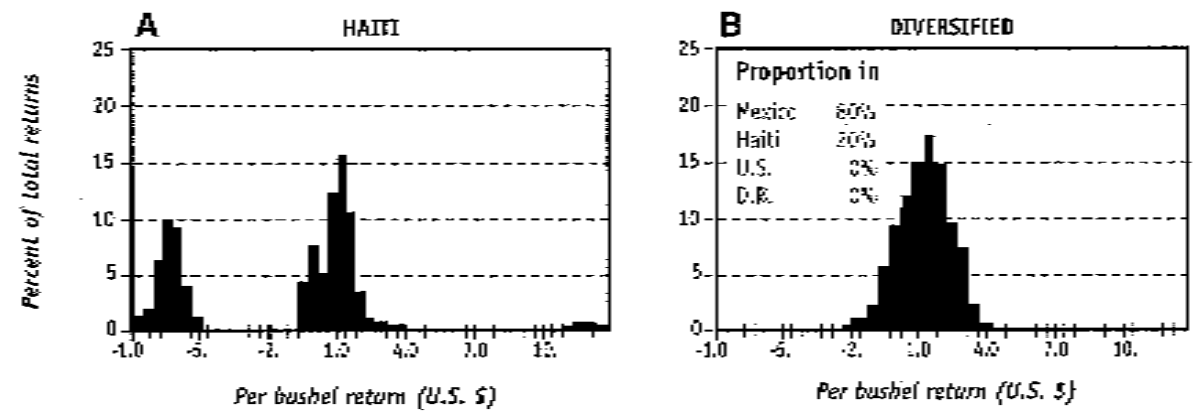

Descriptive statistics for retuans (U.S. \$)

Fig. 4. Per-bushel return and descriptive statistics (U .S. dollars) from investment in processing cucumbers exported either solely from $\mathrm{H}$ aiti or from M exico (80\%) and H aiti (20\%) (diversified) to a U .S. processing facility (W oodstock, III.). Purchasing return is given as percent of total return via air transport at a variable rate based on $\mathrm{M}$ onte $\mathrm{C}$ arlo simulation and sensitivity analysis of data from an investment-risk model.
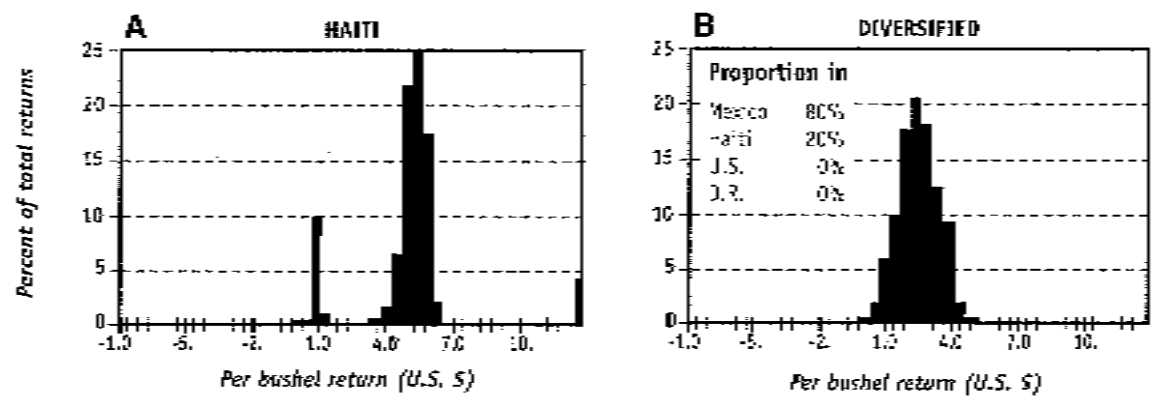

Descriptive statistics for returas (U.S. \$)

\begin{tabular}{|c|c|c|}
\hline & $\bar{x}$ & sD \\
\hline kexico & 8.87 & 1.07 \\
\hline Hait: & 5.22 & $2 . i+4$ \\
\hline Uri-ed Staces & 3.04 & 2.31 \\
\hline [om nicar Repiblic & -4.58 & 241 \\
\hline [inersified & 2.55 & $j_{-5}$ \\
\hline
\end{tabular}

Fig. 5. Per-bushel return and descriptive statistics (U .S. dollars) from investment in processing cucumbers exported either solely from $\mathrm{H}$ aiti or from M exico ( $80 \%)$ and $\mathrm{H}$ aiti $(\mathbf{2 0 \%})$ (diversified) to a U .S. processing facility (W oodstock, III.). Purchasing return is given as percent of total return via sea transport at a fixed rate based on $M$ onte $C$ arlo simulation and sensitivity analysis of data from an investment-risk model. 
pendable(lower SD values) sourcesingle source for cucumber imports during winter months in the U nited States when compared to other sole sourcing opportunities (Fig. 1, panelsB and C). Simulated mean returns from the DR were lower than $\mathrm{M}$ exico, and the predicted range of returns (SD values) from the $D R$ and $H$ aiti were larger than $M$ exico.

If all variation on the major cost component (air freight from $\mathrm{H}$ aiti) was eliminated by an airline contract at $\$ 5.00 /$ bushel $(\$ 0.10 / \mathrm{lb})$, the outcome would favor cucumber import from $\mathrm{H}$ aiti in a diversified strategy (Fig. 2, panel B). H owever, even if the air freight contract is fixed to reduce the mean cost below Mexico, other $\mathrm{H}$ aitian components can vary more than all cost components in M exico (large SD), making import from $\mathrm{H}$ aiti untenable. The diversified mean return (Fig. 2, panel B) decreased $\$ 0.03$ / bushel (M exico: \$1.87; diversified: $\$ 1.84$ ) and the SD decreased $\$ 0.16 /$ bushel (M exico: \$1.07; diversified: $\$ 0.91)$. Thus, under these conditions, thediversified purchasing strategy provided thelowest risk and approximately the same return as purchasing only from M exico.

Diversified investment. Based on sensitivity and $\mathrm{M}$ onte $\mathrm{Carlo}$ analyses, the most favorable diversified investment scenarios among the various transportation methods were: 1) fixed air transport costs where diversification is $20 \% \mathrm{H}$ aiti and $80 \% \mathrm{M}$ exico (Fig. 2, panel B); 2) fixed air transport cost where diversification is $20 \% \mathrm{DR}$ and $80 \%$ M exico (Fig. 3, panel B); 3) variable air transport costs where diversification is $20 \% \mathrm{H}$ aiti and $80 \% \mathrm{M}$ exico (Fig. 4, panel B), and; 4) fixed sea transport costs where $20 \% \mathrm{H}$ aiti and $80 \%$ M exico (Fig. 5, panel B). Comparisonswithin a scenario can be made by contrasting diversified strategies with estimated undiversified returns solely from $\mathrm{H}$ aiti (Figs. 2-5, panel A), the country with the lowest production costs (Frenz and Staub, 1999).

Theoptimum investment scenario for fixed transport was where purchasing diversification was $80 \%$ M exican and $20 \% \mathrm{H}$ aitian (Fig. 2, panel B). A simulation was performed for fixed transport where the diversification strategy was M exico $80 \%$ and D ominican Republic 20\% (Fig. 3, panel B). Purchasing diversification to the DR was not advantageous because mean returnswere lower than diversification involving $\mathrm{M}$ exico and $\mathrm{H}$ aiti (Fig. 2, panel B).

Simulations were conducted for the case where air shipping was available and where costs were set using a distribution in which there was $40 \%$ probability that the freight rate would increase by $\$ 6.00$ (Fig. 4, panel B). The diversification investment strategy for this scenario was M exico $80 \%$, $\mathrm{H}$ aiti $20 \%$ Diversification is clearly not advantageousbecausethe variability in purchasing return is large (mean and SD for investment in $\mathrm{H}$ aiti are 1.11 and 4.21 , respectively) compared to other diversification scenarios (Figs. 2 and 5). If an alternative $\mathrm{H}$ aitian transport method was required $40 \%$ of the time and it cost $\$ 11.00 /$ bushel ( $\$ 6.00$ greater than the preferred rate of $\$ 5.00$ / bushel), then the average return would bealossof $\$ 1.11$ / bushel. M oreover, $68 \%$ of the time the predicted return would rangefrom a profit of $\$ 3.10$ to a loss of $\$ 5.32$ / bushel (calculations not presented). I $\mathrm{n}$ addition, the diversified investment of $80 \%$ $\mathrm{M}$ exico and $20 \% \mathrm{H}$ aitian investment may not be preferred to $100 \% \mathrm{M}$ exican investment because risk caused by a fluctuating ratefor transport fro $\mathrm{m} \mathrm{H}$ aiti is too great (SD $=1.16$ ).

If the frequency of sea transportation from $\mathrm{H}$ aiti improved and was available for transport of cucumbers, then the mean transport cost could drop significantly (Frenz, 1996). Simulation experimentsconsidered the possibility of sea transport at an average fixed cost of $\$ 4.00 /$ bushel. A comparison can be made between a diversified purchasing strategy of M exico $80 \%$ and $\mathrm{H}$ aiti $20 \%$ (Fig. 5, panel B) and investment solely in M exico (Fig. 1, panel A). D iversified purchasing for this scenario increased the mean return by $\$ 0.68$ / bushel (diversified at $\$ 2.55$ less $M$ exico at \$1.87) and decreased therisk by $\$ 0.11 /$ bushel (M exico at $\$ 1.07$ less diversified at \$0.96). Thus, thisscenario illustrates that a competitive diversified strategy using $\mathrm{M}$ exico and $\mathrm{H}$ aiti might be a sound investment strategy given the variables considered. H owever, given the fact that Port-au-Prince harbor facilities are not well maintained or extremely efficient and that other ports are not in close proximity [within 97 $\mathrm{km}$ (60 miles)] to cucumber growing regions (e.g., Cap-H aitien), it might be difficult to implement this purchasing strategy.
The diversification strategy for fixed air transport where $M$ exico comprises $80 \%$ and $\mathrm{H}$ aiti $20 \%$ of the expected imports (Fig. 2, panel B) can be compared to those of variable air (Fig. 4, panel B) and fixed sea (Fig. 5, panel B) transport. Based on mean and SD, the diversified strategy of fixed sea transport was a superior investment to fixed and variable air transport with the same investment allocation between countries. Thus, the optimum scenario identified by the investmentrisk model was sea freight from $\mathrm{H}$ aiti.

Bimodal distributionsoccur when conditionsimposed on theinvestmentrisk model yield observations grouped in two or more clusters. Graphic depictions of development activities in developing areas are often bimodal (Fig. 1, panel C, panel A in Figs. 2-5). For instance, in a variable air transport, $\mathrm{H}$ aiti's freight costs were set to allow for a low freight $60 \%$ of the time to reflect theairline'sadjustment in freight rate during low demand periods (Fig. 4, panel A). Thus, the model's algorithm allowed for a depiction of data in which periods of lower cost might be observed by assigning a probability value. Comparative analysis using this model criteria indicated that purchasing solely from M exico was preferred under conditions of a variableair transport scenario from $\mathrm{H}$ aiti (Fig. 1, panel A vs. Fig. 4, panel A).

INVESTMENT STRATEgies. Purchasing strategies which strive to maximize the short-term profits of U .S. processorstend to disregard purchasing-price trends in M exico and price increases caused by production failures. Such strategies often manage with discrete budgets which ignore possible outcomes of inclement weather and pest infestation that cause price increases. Such variables can often be managed by location diversification.

Resistance to change and transition from production of one crop species to another (e.g., banana, sugar cane, or coffee production to processing cucumber) may be decreased by repetition of cucumber production trials by $\mathrm{H}$ ispaniola growers. Future attempts at cultivating processing cucumber on $\mathrm{H}$ ispaniola should incorporate avenues which allow growers more time to acquire resources and to integratecucumber production into their crop management schedule. Such repetition requires systematic production trials by growers and responsive, 
well-trained agricultural extension personnel.

A financial analysis of agri-industrial investments describes success as dependent on multiple factors including price and volume (Brown, 1993). The relationships of these factors are measured by solvency, profitability and risk-bearing ability. The U .S. processors' financial analysis influences the purchasing decisions to diversify from $M$ exico to the Caribbean. Similarly, the growers' financial analysis influences the distribution decisions to diversify among processing, brining and fresh market production to reduce overall marketing risk. Finally, an airlines' financial analyses can affect the freight classification and thus the rate decisionsto diversify among lower rate U .S. bound cucumbers and the higher rate of other freight. In each instance, diversification among suppliersor customerscan reduceoverall financial risk.

Financial theorists assume that investors (e.g., U.S. processors and Caribbean growers) are risk adverse and anticipate a risk premium to hold investmentswith uncertain future rates of return (Bodie et al., 1989). In our study, an investment-risk model was used to test various scenarios determined by strategic alliances and investment diversification strategies. Information obtained for this model allowed for investment decision-making based on risk analysis. The investment-risk model tested whether strategic alliances among U .S. cucumber processors and $\mathrm{H}$ ispaniolagrowers could reduce overall costs and financial risks to satisfy competitive investment criterion. This position is supported by the fact that the $\mathrm{H}$ ispaniola transport risks are greater than transport risks from M exico. In addition, the model tested whether strategic alliances among U .S. cucumber processors, $\mathrm{H}$ ispaniolagrowersand airlines could reduce overall costs and financial risks to satisfy investment. It was determined that such alliances could allow transport risks and coststo be competitive with M exico.

\section{Literature cited}

Bodie, Z., A. Kane, and A.J . M arcus. 1989. Investments. Richard D. I rwin, Inc., Boston, $M$ ass.

Brigham, E.F. and L.C. Gapenski. 1988. Financial management: Theory and practice. 5th ed. Dryden Press, C hicago, III.

Brown, J.G. 1993. Agro-industrial investment and operations. World Bank, Wash., DC.

Brown, M. and I. Goldin. 1992. The future of agriculture: D eveloping country implications. O rg. E con. Coop. D ev., Paris, France.

Frenz, B.L. 1996. Strategic risk management for international business development of a processing cucumber industry in the Caribbean, PhD. diss. (abstr. AAC 9622522). U niv. Wis., M adison.

Frenz, B.L. and J.E. Staub. 1999. Establishing cucumber production in lesser developed countries: An absolute cost advantage of $\mathrm{M}$ exico versus $\mathrm{H}$ ispaniola producers. H ortT echnology 9(3):466-472.

Knight, F.H . 1921. Risk, uncertainty and profit. Houghton Mifflin and Co., New York, NY.

N iehans, J. 1968. Reflections on Shackle, probability, and our uncertainty about uncertainty, p. 21-23. In J.D. H ammond (ed.). Essays in the theory of risk and insurance. Scott, Foresman and $\mathrm{Co}$., Glenview, III.

Picciotto, R. 1994. Visibility and disappointment: The new role of development evaluation, p. 210-230. In L. Rodwin and D.A. Schon (eds.). Rethinking the development experience: Essays provoked by the work of Albert $\mathrm{O}$. Hirschman. Brookings I nst.-L incoln I nst. L and Policy, Cambridge, $M$ ass.

SASI nstitute, Inc. . 1988. SAS/ ST AT user's guide: Version 6.03. SAS I nst., Cary, N C.

Seal, H . L . 1969. Stochastic theory of arisk business. Wiley, N ew York.

Snedecor, G.W. and W.G. Cochran. 1967. Statistical methods. I owaStateU niv. Press, Ames.

Staub, J [ack] E. H ome page. 1 J une 1999 বttp:/ / ipcm.wisc.edu/ hort/ usdavcru/ >.

U SD A. 1991. L atin America and the Caribbean: Selected economic and social data. Agency I ntl. Dev., Wash., D C.- 